https://helda.helsinki.fi

\title{
Label-free tissue proteomics can classify oral squamous cell carcinoma from healthy tissue in a stage-specific manner
}

\section{Dickinson, Amy}

2018-11

Dickinson , A , Saraswat , M , Mäkitie , A , Silen , R , Hagström , J , Haglund , C , Joenväärä , S \& Silen , S 2018 , ' Label-free tissue proteomics can classify oral squamous cell carcinoma from healthy tissue in a stage-specific manner ' , Oral Oncology, vol. 86 , pp. 206-215 . https://doi.org/10.1016/j.oraloncology.2018.09.013

http://hdl.handle.net/10138/265533

https://doi.org/10.1016/j.oraloncology.2018.09.013

publishedVersion

Downloaded from Helda, University of Helsinki institutional repository.

This is an electronic reprint of the original article.

This reprint may differ from the original in pagination and typographic detail.

Please cite the original version. 


\title{
Label-free tissue proteomics can classify oral squamous cell carcinoma from healthy tissue in a stage-specific manner
}

\author{
Amy Dickinson $^{\mathrm{a}, \mathrm{b}, *, 1}$, Mayank Saraswat ${ }^{\mathrm{a}, \mathrm{d}, 1}$, Antti Mäkitie ${ }^{\mathrm{b}, \mathrm{e}}$, Robert Silén ${ }^{\mathrm{a}}$, Jaana Hagström ${ }^{\mathrm{d}, \mathrm{h}}$, \\ Caj Haglund ${ }^{\mathrm{f}, \mathrm{g}}$, Sakari Joenvääräa, ${ }^{\mathrm{a}, \mathrm{d}}$, Suvi Silén ${ }^{\mathrm{b}, \mathrm{c}}$ \\ a Transplantation Laboratory, Haartman Institute, University of Helsinki, Haartmaninkatu 3, PO Box 21, 00014, Finland \\ ${ }^{\mathrm{b}}$ Department of Otorhinolaryngology - Head and Neck Surgery, University of Helsinki and Helsinki University Hospital, Helsinki, Finland \\ ${ }^{\mathrm{c}}$ Department of Biosciences and Nutrition, Karolinska Institutet, Stockholm, Sweden \\ ${ }^{\mathrm{d}}$ HUSLAB, Helsinki University Hospital, Helsinki 00290, Finland \\ e Division of Ear, Nose and Throat Diseases, Department of Clinical Sciences, Intervention and Technology, Karolinska Institutet and Karolinska University Hospital, \\ Stockholm, Sweden \\ ${ }^{\mathrm{f}}$ Department of Surgery, University of Helsinki and Helsinki, University Hospital, Helsinki, Finland \\ ${ }^{g}$ Research Programs Unit, Translational Cancer Biology, University of Helsinki, Helsinki, Finland \\ ${ }^{\mathrm{h}}$ Department of Pathology, University of Helsinki, Finland
}

\section{A R T I C L E I N F O}

\section{Keywords:}

Oral squamous cell carcinoma

Head and neck cancer

Tongue cancer

OPLS-DA

Tissue proteomics

CA1

S100A7

Neutrophil defensin 1

ANP32B

Immunohistochemistry

\begin{abstract}
A B S T R A C T
Objectives: No prognostic or predictive biomarkers for oral squamous cell carcinoma (OSCC) exist. We aimed to discover novel proteins, altered in OSCC, to be further investigated as potential biomarkers, and to improve understanding about pathways involved in OSCC.

Materials and Methods: Proteomic signatures of seven paired healthy and OSCC tissue samples were identified using ultra-definition quantitative mass spectrometry, then analysed and compared using Anova, principal component analysis, hierarchical clustering and OPLS-DA modelling. A selection of significant proteins that were also altered in the serum from a previous study (PMID: 28632724) were validated immunohistochemically on an independent cohort $(n=66)$ to confirm immunopositivity and location within tumour tissue. Ingenuity Pathways Analysis was employed to identify altered pathways.

Results: Of 829 proteins quantified, 257 were significant and 72 were able to classify healthy vs OSCC using OPLS-DA modelling. We identified 19 proteins not previously known to be upregulated in OSCC, including prosaposin and alpha-taxilin. KIAA1217 and NDRG1 were upregulated in stage IVa compared with stage I tumours. Altered pathways included calcium signalling, cellular movement, haematological system development and function, and immune cell trafficking, and involved NF-kB and MAPK networks.

Conclusions: We found a set of proteins reliably separating OSCC tumour from healthy tissue, and multiple proteins differing between stage I and stage IVa OSCC. These potential biomarkers can be studied and validated in larger cohorts.
\end{abstract}

\footnotetext{
Abbreviations: ALYREF, THO complex subunit 4; ANP32B, Acidic leucine-rich nuclear phosphoprotein 32 family member B; AUROC, area under the receiver

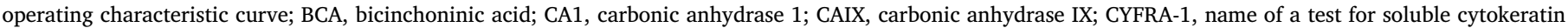

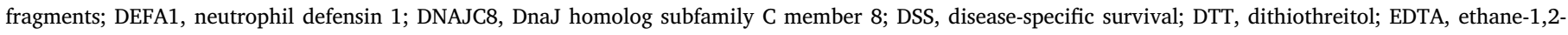

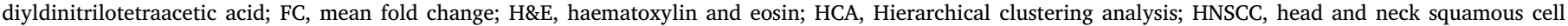

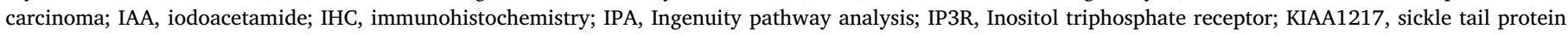

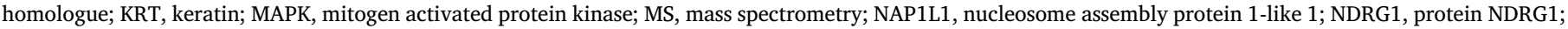

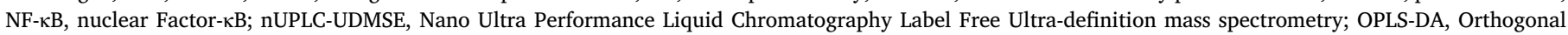

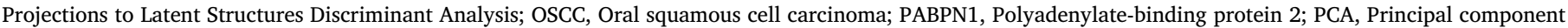

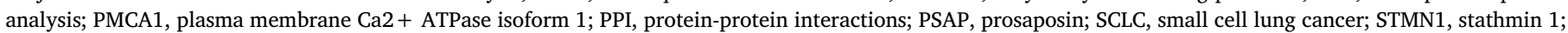
TMA, tissue microarray; TNM, tumour-node-metastasis; TPA, cytokeratin detection test

* Corresponding author at: Transplantation Laboratory, Haartman Institute, University of Helsinki, Haartmaninkatu 3, PO Box 21, 00014, Finland.

E-mail addresses: Amy.dickinson@helsinki.fi (A. Dickinson), sarawat.mk@gmail.com (M. Saraswat), antti.makitie@helsinki.fi (A. Mäkitie), robert.silen@iki.fi (R. Silén), jaana.hagstrom@hus.fi (J. Hagström), caj.haglund@helsinki.fi (C. Haglund), sakari.joenvaara@helsinki.fi (S. Joenväärä), suvi.silen@helsinki.fi (S. Silén).

${ }^{1}$ These authors contributed equally to this work.
} 


\section{Introduction}

Oral squamous cell carcinoma (OSCC) is the most common type of head and neck cancer globally with an annual incidence of around 275 000 [1]. It is more prevalent in men, and prevalence is increasing [2]. In particular, tongue cancer incidence has been rising in various parts of the world in recent years, and especially in patients under $45[1,3]$. Strong risk factors include alcohol and tobacco.

Western 5-year survival rates for oral cavity cancer are around $60 \%$ [3-5]. Five-year disease- specific survival (DSS) of OSCC of the mobile tongue decreases as the stage increases. In Finland, 5-year DSS is $87 \%$ for stage I carcinomas, but $51 \%$ for stage IV. Interestingly, recurrence occurred in $22-34 \%$ of patients, slightly varying by stage [6].

However, the TNM classification does not fully account for OSCC patients' outcomes [7]; tumours with the same TNM stage can exhibit different behaviours, treatment responses, and prognoses [8]. Different molecules and pathways have been linked with OSCC cancer behaviours, such as the VEGF-Flt-1 pathway with invasion [9], kallikreinrelated peptidase with metastatic capacity [10], and glutathione-peroxidase-I overexpression with poor prognosis [11]. None of these are yet in clinical use.

Nano Ultra-Performance Liquid Chromatography Label-Free UltraDefinition Mass Spectrometry (nUPLC-UDMS ${ }^{\mathrm{E}}$ ) is a highly sensitive form of mass spectrometry (MS), capable of quantifying hundreds-tothousands of proteins in solution. nUPLC-UDMS ${ }^{\mathrm{E}}$ discovery-driven analysis offers a unique avenue to discover proteins and pathways that are previously not known to be altered in OSCC. Previously, studies using non-pooled paired healthy and OSCC tissue samples for direct comparison with MS have used a gel-based matrix to register the differences between the cases and controls after which protein spots are identified using MS [12-14]. However, shotgun proteomics, as done here, and the electrophoresis approaches have different scopes and limitations. Electrophoresis mainly homes in on critical alterations such as isoform differences, and post-translational modifications, whereas shotgun approaches aim for a broad overview of proteomic changes, including those with smaller abundances, and allows for novel protein discovery. These two approaches can be complementary [15].

The primary aim of this study was to identify and quantify the differences between healthy tissue and OSCC using nUPLC-UDMS ${ }^{\mathrm{E}}$ proteomics. In particular, we aimed to discover novel proteins with significantly different expression in OSCC compared with controls, along with differences in protein expression between high- and lowgrade tumours. This will facilitate future research to assess whether these proteins can be used as potential new prognostic or predictive biomarkers, for example predicting different clinical behaviours of OSCCs. Additionally, the discovery of proteins involved can help in identifying important pathways in OSCC pathogenesis and thus potential therapeutic targets.

\section{Materials and methods}

Briefly, tissues of primary OSCC of the mobile tongue, and paired healthy tongue epithelium were taken preoperatively and immediately frozen. At the time of analysis, the tissues were thawed and lysed, and protein extraction was performed. The proteins were trypsin digested, and the tryptic peptide mixture was analysed using mass spectrometry (nUPLC-UDMS ${ }^{\mathrm{E}}$ ), to identify proteins differing between OSCC and paired healthy epithelium. Statistical classification and separation techniques were performed to ensure clear differences between OSCC and healthy tissue. Pathway analysis using two methods were performed to assess altered pathways within OSCC to gain greater understanding. We additionally performed a comparison between stage I and stage IVa OSCC. Selected proteins that have previously been found to be altered in serum of OSCC $[16,17]$ and that we also found to be altered in the tissue were validated with immunohistochemistry (IHC). A tissue microarray block of 66 patients with oral tongue OSCC was used for this
IHC analysis. Patient and tumour information is in Supplementary Table 1. Detailed information about the materials and methods are found in Supplementary File 1. The workflow can be visualised in Fig. 1.

Ethical approval was granted by the institutional Research Ethics Committee at the Helsinki University Hospital (Dnro: 64/13/03/02/ 2014). All patients provided informed written consent to participate in the study.

\section{Results}

Proteomics of OSCC and healthy tongue tissue

Of 829 proteins with two or more unique peptides that were quantified, 257 proteins were statistically significant (Supplementary Table 2).

The majority of proteins were present in both the cancer and control tissue in differing amounts, but one protein (alpha-taxilin) was absent

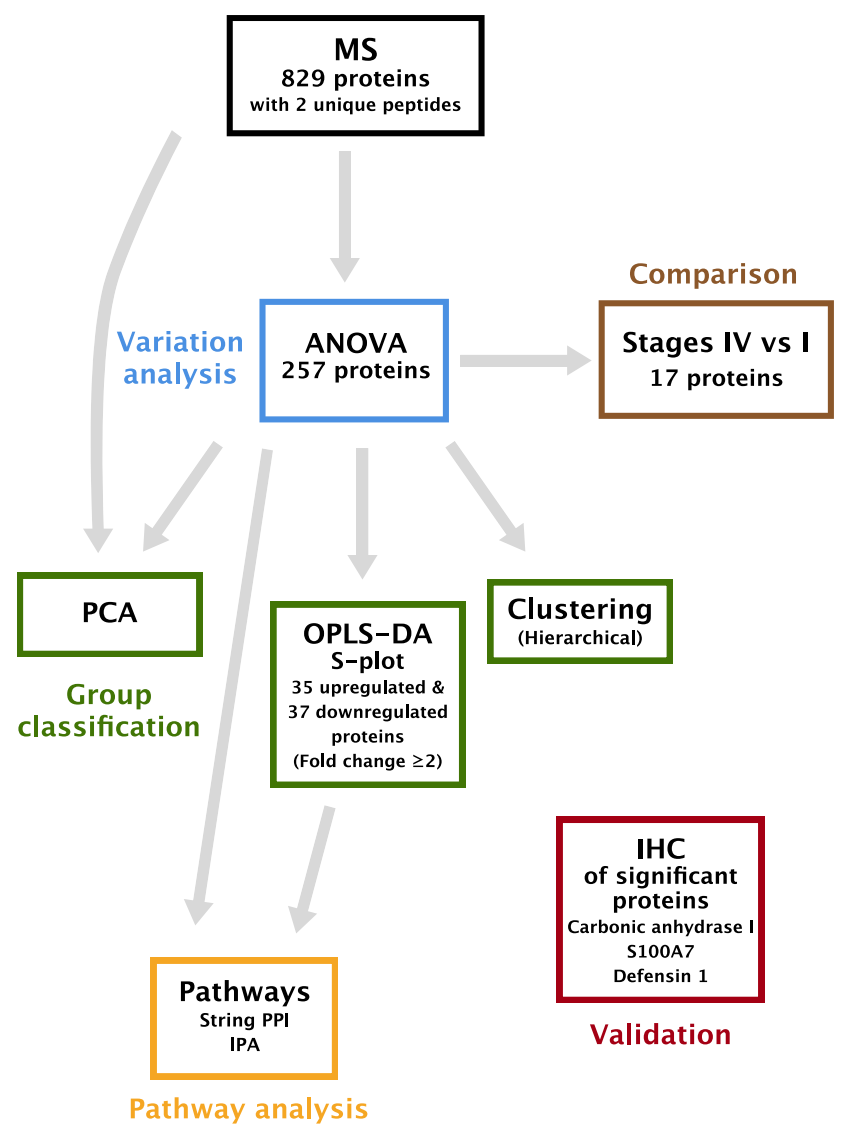

Fig. 1. Overview of methods employed, and results obtained. Mass spectrometry using nUPLC-UDMS ${ }^{\mathrm{E}}$ (Nano Ultra Performance Liquid Chromatography Label Free Ultra-definition mass spectrometry was performed on OSCC of the tongue and paired healthy controls. Anova analysis was performed on these, with a p-value cut-off of 0.05 . For group classification, PCA, OPLS-DA and Hierarchical Clustering Analysis were used, and significant proteins were identified using OPLS-DA analysis. Using String PPI and IPA, pathways altered in OSCC were identified. Furthermore, stage IVa vs stage I OSCC protein expressions were compared. Validation was performed on selected proteins, to confirm their presence is consistent in tumour samples, and to identify which cells within the tumour express these proteins. These proteins are known to be significantly altered in OSCC serum compared to controls in a previous study [16]. Key: ANOVA - Analysis of Variance; IHC - immunohistochemistry; IPA Ingenuity Pathways Analysis; MS - mass spectrometry; OPLS-DA - Orthogonal Projections to Latent Structures Discriminant Analysis; PCA - Principal Component Analysis; String PPI - Protein-protein Interaction (via String). 
A

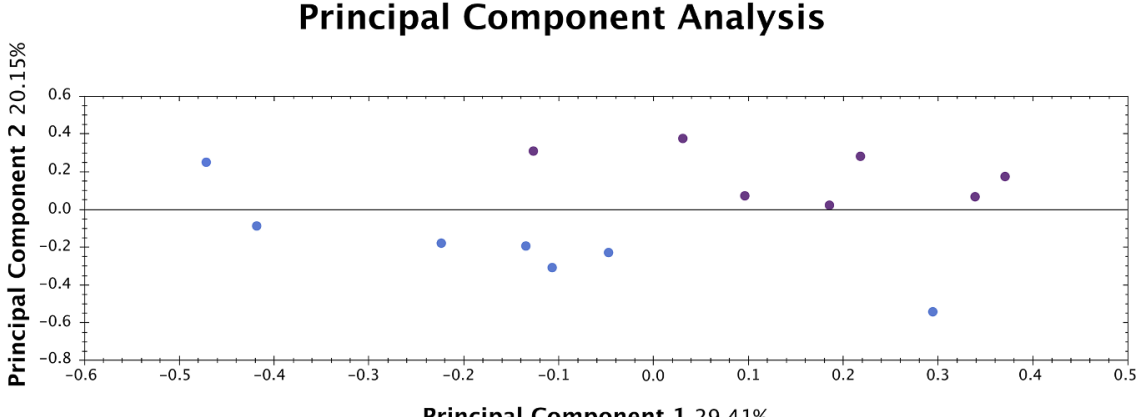

B

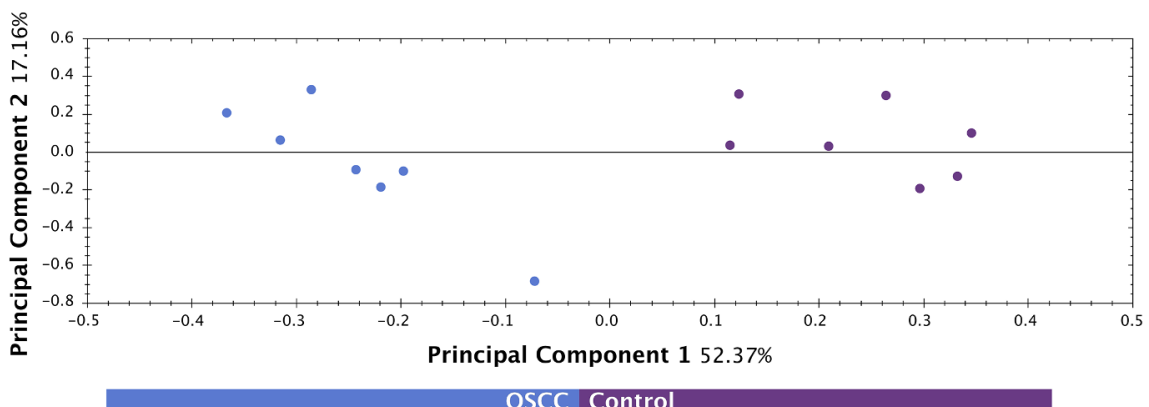

Fig. 2. Separation between the OSCC proteins demonstrated with three different methods. Principal Component Analysis when all the proteins (two or more unique peptides) were considered is shown in Panel A. Principal Component Analysis, when using proteins passing Anova cutoff p-value of 0.05 , is shown in Panel B. Visualisation of OPLS-DA (Orthogonal Projections to Latent Structures Discriminant Analysis) modelling by S-plot, gave us the significantly different proteins, which could classify the OSCC from healthy tissue, is shown in Panel C. The upper right quadrant (with positive values) show proteins upregulated in OSCC tongue tissue; the lower left quadrant (with negative values) shows the proteins upregulated in the healthy tongue tissue. The cut-off used to separate significantly different proteins from other proteins was \pm 0.7 . The blue line represents the cut-off for proteins upregulated in OSCC, the purple line represents the cut-off for proteins downregulated in OSCC. Hierarchical clustering, using the Euclidean Similarity Index, shows branching between the OSCC and paired healthy tissue based on protein expression (Panel D). (For interpretation of the references to colour in this figure legend, the reader is referred to the web version of this article.)
C

\section{S- plot $($ Control $=-1$, OSCC $=1)$}

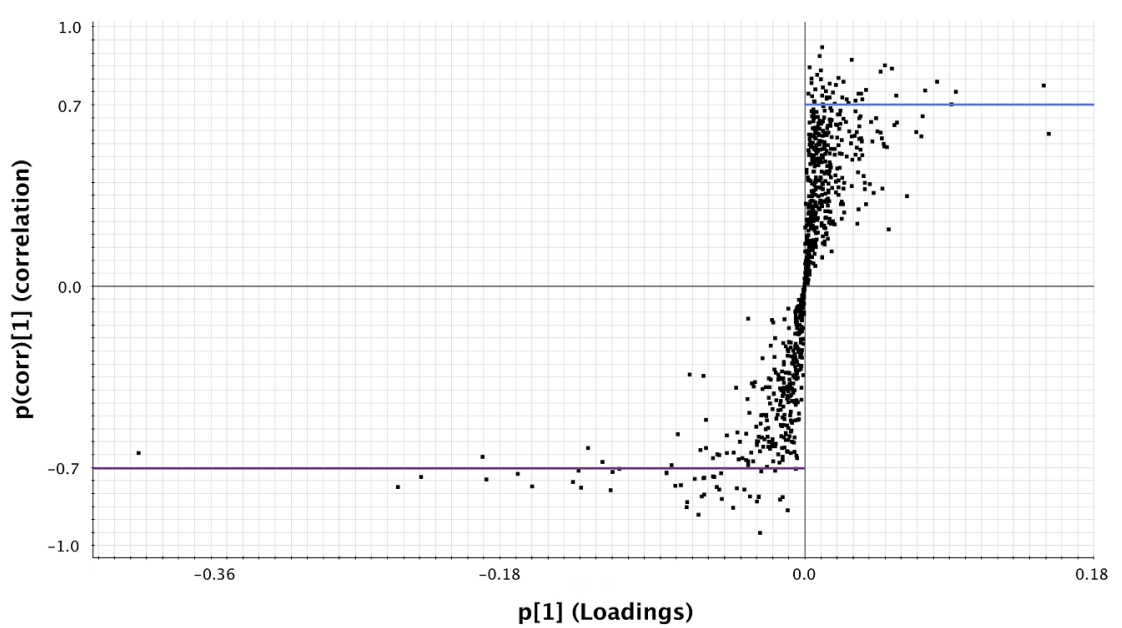

D

\section{Hierarchical Cluster Analysis}

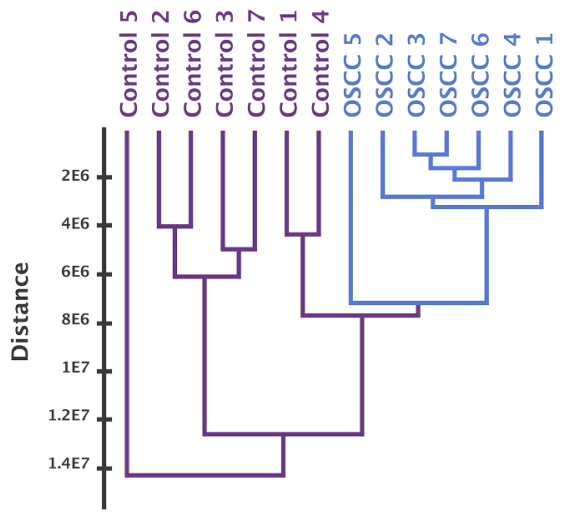


in 5 of the 7 control samples, with low levels in the other two samples. Other highly upregulated proteins include neutrophil defensin 1 (DEFA1), and sickle tail protein homologue (KIAA1217), with mean fold changes (FC) of 18.2 and 18, respectively.

For confirmation of the separation and for further filtering of the proteins differing between the OSCC and healthy control tissue samples, various supervised and unsupervised statistical analyses were employed: Principal Component Analysis (PCA); Orthogonal Projections to Latent Structures Discriminant Analysis (OPLS-DA); Hierarchical Clustering Analysis (HCA). In all three of these analyses there was a clear separation between the OSCC and control tissues. HCA showed separate branches of OSCC and healthy samples based on protein abundances (Fig. 2d).

PCA was used to determine and visualise the principal axes of protein abundance variation between the two groups. This showed a complete separation between cancer and healthy tissue when using all 829 proteins, with the separation becoming even clearer when just the statistically significant proteins were included (Fig. 2a and b).

OPLS-DA was used to model the differences between the two groups. One OSCC tissue sample from patient number two was removed as it lay beyond the $95 \%$ confidence range. An S-plot was generated from the data (Fig. 2c). Proteins exceeding the p(corr) cut-off value of \pm 0.7 were considered to be significant (Table 1). 35 upregulated and 37 downregulated proteins with FC of 2 or more were found in this s-plot, such as DEFA1 (FC 19.8; p(corr) 0.84), S100A7 (FC 5.1; p(corr) 0.85 ), carbonic anhydrase 1 (CA1) (FC 3.3; p(corr) 0.92). of these S-plot proteins had an area under the receiver operating characteristic curve (AUROC) of 1.0.

Comparison between proteomic signatures of the stage I and stage IVa OSCC

The proteomic differences between stage I and stage IVa OSCC were performed using the same methods as for the tumours versus controls. There were 17 protein differences with Anova $\mathrm{p}<0.05$, which can be seen in Table 2. The most upregulated of these being KIAA1217 (FC 4.94) and NDRG1 (FC 4.12). The most downregulated proteins were cytochrome b-c1 complex (FC -2.64) and heat shock protein HSP 90 alpha (FC -2.61). There was some overlap on PCA when using all the 827 proteins (Fig. 3a), however upon using the statistically significant proteins, there was a clear separation between stage I and stage IVa (Fig. 3b).

\section{Immunohistochemistry of carbonic anhydrase 1 (CA1), S100A7, and neutrophil defensin 1 (DEFA1)}

CA1, S100A7 and DEFA1 were proteins, which were also found to be altered in the serum of OSCC patients [17], as well being some of the most differentiating tissue proteins after OPLS-DA modelling. IHC of these proteins was performed on an independent tissue microarray (TMA) block cohort of OSCCs, and separate healthy tissue samples from OSCC patients. This confirmed stronger staining in OSCC than healthy epithelium. S100A7 showed heterogeneous cytoplasmic, membranous and nuclear positivity in tumour tissue, whereas in the controls positivity was present in only the epithelial keratin layer. DEFA1 immunopositivity was strong in tumour cells, both cytoplasm and nuclei, and additional positivity was detected in inflammatory cells surrounding the cancer tissue. In the control tissue, positivity was cytoplasmic throughout the epithelium, with more intense, and additional membranous positivity in the basal cell layers. CA1 showed moderate cytoplasmic positivity throughout the tumour tissue, and also membranous positivity in some tumours. Inflammatory cells also had immunopositivity. In the controls, positivity was localised to the epithelium, and was stronger in the basal layer. Fig. 4 shows examples of, and the proportions of mild, moderate and strong tumour staining positivity by intensity in the tumour.

\section{Pathway analysis of OSCC tissue}

We performed two analytical methods to determine the important networks and pathways altered in OSCC compared to healthy tissue. String protein-protein interactions (PPI) shows direct connections linking the S-plot proteins as shown in Fig. 5, where there are clusters of cytoskeletal proteins such as myosin and tropomyosin chains, and clusters of nuclear proteins such as ALYREF (THO complex subunit 4), NAP1L1 (nucleosome assembly protein 1-like 1), PABPN1 (Polyadenylate-binding protein 2), DNAJC8 (dnaJ homolog subfamily C member 8). Ingenuity pathway analysis (IPA) shows the significantly altered networks in OSCC, i.e. those enriched in the S-plot proteins. IPA includes proteins via which these proteins are known to interact, thus filling in the gaps of the proteins that may not have been detected. The top networks enriched were 1: 'Cellular movement, haematological system development and function, immune cell trafficking', 2: 'Hereditary disorder, organismal injury and abnormalities, skeletal and muscle disorders, 3: 'Cell-to-cell signalling and interaction, cellular movement, nervous system development and function', 4: 'Infectious diseases, dermatological diseases and condition, organismal injury and abnormalities'. These are all significant and highly enriched networks, with network scores between 31 and 56, and enriched with 16 to 25 proteins. This method verifies the s-plot proteins' significance on a pathway level. The overlay of both network analysis methods further shows that there is crossover between all of these OSCC networks. For example, a connection between ALYREF (THO complex subunit 4) and DNAJC8 connects Networks 2 and 3, connections between stathmin 1 (STMN1) and tropomyosins (connecting Networks 1 and 2).

IPA also identified significant canonical pathways enriched with the $\mathrm{p}<0.05$ proteins (Supplementary Fig. 1). The top canonical pathways include calcium signalling, regulation of actin-based motility by Rho, actin cytoskeleton signalling and tight junction signalling.

\section{Discussion}

OSCC is often detected late with the consequences of poor survival. Treatment can also be functionally impairing. OSCC incidence is increasing and has a high recurrence rate [6]. The disease course is unpredictable, without any established biomarkers for prognostication or prediction. Such biomarkers are needed urgently. Additionally, it is imperative to uncover the pathobiology of OSCC at the tissue level to identify potential treatment targets.

\section{Proteomic comparisons}

nUPLC-UDMS ${ }^{\mathrm{E}}$ discovery-driven analysis offers a unique avenue to discover proteins and pathways that are previously not known to be altered in OSCC. Some similar patterns were found, when compared to previous proteomic studies [12-14] such as proteasome activator, peripherin, keratin (KRT) 17 and cofilin-1 upregulation [12], downregulation of cytoskeletal proteins such as myosin light and heavy chains, tropomyosins (except upregulation of tropomyosin 4) [14], and upregulation of matrix-metalloproteinase $9, \mathrm{~S} 100 \mathrm{~A} 7$, thymosin beta 10, tenascin C, calreticulin, and downregulation of lumican [18].

The 257 proteins significantly differing between OSCC and healthy tissue were further modelled using OPLS-DA, which classifies samples based on their protein signature and shows their separation and similarities in a way that is difficult to obtain using other means. Among the S-plot proteins generated from this analysis (Table 1), there were 19 proteins, which to our knowledge are not previously known to be upregulated in OSCC, although some have been found in other cancers. These could be further studied as potential biomarkers. Those with the greatest abundance include prosaposin (PSAP) and Acidic leucine-rich nuclear phosphoprotein 32 family member B (ANP32B). The rest are found in Table 1, along with p-value, fold change and AUROC information. ANP32B, with an AUROC of 0.939, is upregulated in 
Table 1

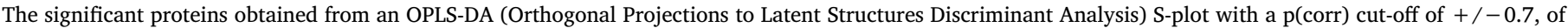

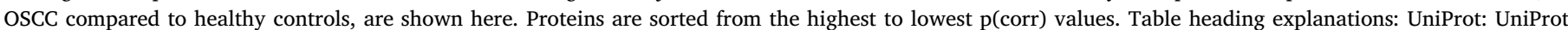

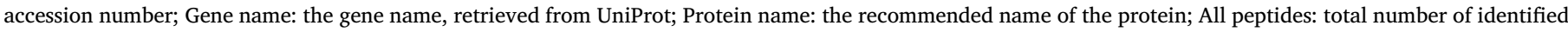

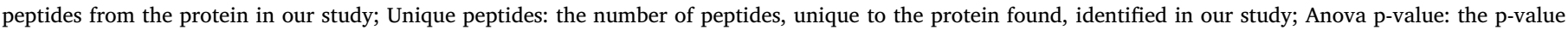

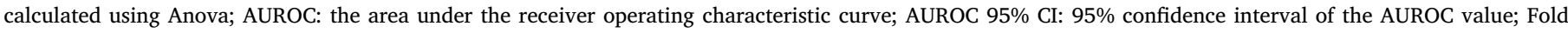

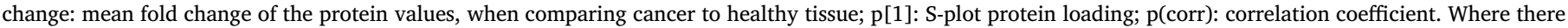

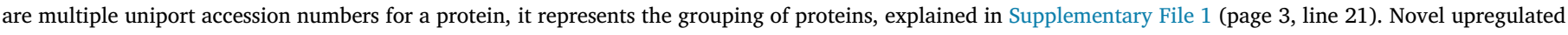
proteins in OSCC tissue are shown in bold.

\begin{tabular}{|c|c|c|c|c|c|c|c|c|c|c|}
\hline UniProt & Gene name & Protein name & All peptides & $\begin{array}{l}\text { Unique } \\
\text { peptides }\end{array}$ & Anova p-value & AUROC & $\begin{array}{l}\text { AUROC } \\
95 \% \mathrm{CI}\end{array}$ & $\begin{array}{l}\text { Fold } \\
\text { change }\end{array}$ & $\mathbf{p}[1]$ & $\begin{array}{l}\mathbf{p}(\text { corr }) \\
{[1]}\end{array}$ \\
\hline P00915 & CA1 & Carbonic anhydrase 1 & 8 & 8 & $9.11 \mathrm{E}-04$ & 1.00 & - & 3.3 & 0.01 & 0.92 \\
\hline Q86U42 & PABPN1 & Polyadenylate-binding protein 2 & 5 & 2 & 4.99E-04 & 1.00 & - & 3.1 & 0.01 & 0.89 \\
\hline Q01105;P0DME0 & SET & Protein SET & 24 & 17 & $1.72 \mathrm{E}-03$ & 0.96 & $0.83-1$ & 1.9 & 0.03 & 0.87 \\
\hline P31151 & S100A7 & Protein S100-A7 & 31 & 14 & $6.58 \mathrm{E}-03$ & 0.96 & $0.84-1$ & 5.1 & 0.05 & 0.85 \\
\hline A0A0B4J269 & $N / A$ & Uncharacterized protein & 16 & 2 & $5.60 \mathrm{E}-03$ & 1.00 & - & 3.1 & 0.00 & 0.84 \\
\hline P59665;P59666 & DEFA1 & Neutrophil defensin 1 & 8 & 7 & $1.79 \mathrm{E}-03$ & 1.00 & - & 19.8 & 0.05 & 0.84 \\
\hline Q96K17 & BTF3L4 & Transcription factor BTF3 homolog 4 & 3 & 2 & 1.37E-04 & 0.92 & $0.74-1$ & 4.6 & 0.01 & 0.83 \\
\hline P63313 & TMSB10 & Thymosin beta- 10 & 5 & 4 & 1.07E-02 & 1.00 & - & 3.6 & 0.05 & 0.83 \\
\hline Q8N6V9 & TEX9 & Testis-expressed sequence 9 protein & 3 & 2 & 2.07E-03 & 0.98 & $0.90-1$ & 3.9 & 0.01 & 0.81 \\
\hline P67809 & $Y B X 1$ & $\begin{array}{l}\text { Nuclease-sensitive element-binding } \\
\text { protein } 1\end{array}$ & 8 & 4 & $9.35 \mathrm{E}-03$ & 0.96 & $0.84-1$ & 4.3 & 0.02 & 0.80 \\
\hline Q86SG5 & S100A7A & Protein S100-A7A & 15 & 2 & $1.32 \mathrm{E}-02$ & 0.96 & $0.84-1$ & 18.3 & 0.00 & 0.80 \\
\hline Q15468 & STIL & SCL-interrupting locus protein & 3 & 3 & $7.25 \mathrm{E}-03$ & 0.96 & $0.84-1$ & 4.8 & 0.01 & 0.80 \\
\hline Q9Y2V2 & CARHSP1 & Calcium-regulated heat-stable protein 1 & 8 & 6 & $3.01 \mathrm{E}-03$ & 0.94 & $0.80-1$ & 2.4 & 0.02 & 0.79 \\
\hline P27797 & $C A L R$ & Calreticulin & 47 & 38 & $9.26 \mathrm{E}-04$ & 0.94 & $0.76-1$ & 2.4 & 0.08 & 0.79 \\
\hline O75937 & DNAJC8 & DnaJ homolog subfamily C member 8 & 5 & 2 & 2.02E-02 & 0.88 & $0.67-1$ & 2.2 & 0.00 & 0.78 \\
\hline Q96MG8 & PCMTD1 & $\begin{array}{l}\text { Protein-L-isoaspartate } \mathrm{O} \text { - } \\
\text { methyltransferase domain-containing } \\
\text { protein } 1\end{array}$ & 3 & 2 & $1.45 \mathrm{E}-02$ & 0.96 & $0.84-1$ & 1.8 & 0.02 & 0.78 \\
\hline P55209 & NAP1L1 & Nucleosome assembly protein 1 -like 1 & 15 & 11 & $1.13 \mathrm{E}-02$ & 0.94 & $0.76-1$ & 3.2 & 0.02 & 0.77 \\
\hline Q96AG4 & LRRC59 & Leucine-rich repeat-containing protein 59 & 3 & 2 & $1.10 \mathrm{E}-02$ & 0.92 & $0.71-1$ & 3.6 & 0.01 & 0.77 \\
\hline A6NDA9 & LRIT2 & $\begin{array}{l}\text { Leucine-rich repeat, immunoglobulin- } \\
\text { like domain and transmembrane } \\
\text { domain-containing protein } 2\end{array}$ & 2 & 2 & $3.36 \mathrm{E}-02$ & 0.86 & $0.60-1$ & 2.7 & 0.01 & 0.76 \\
\hline Q92688 & ANP32B & $\begin{array}{l}\text { Acidic leucine-rich nuclear } \\
\text { phosphoprotein } 32 \text { family member B }\end{array}$ & 17 & 8 & $4.35 \mathrm{E}-03$ & 0.94 & $0.76-1$ & 2.1 & 0.04 & 0.76 \\
\hline P67936 & TPM4 & Tropomyosin alpha-4 chain & 63 & 18 & $6.36 \mathrm{E}-04$ & 0.94 & $0.80-1$ & 2.4 & 0.07 & 0.75 \\
\hline P53999 & SUB1 & $\begin{array}{l}\text { Activated RNA polymerase II } \\
\text { transcriptional coactivator } \mathrm{p} 15\end{array}$ & 5 & 4 & $1.45 \mathrm{E}-02$ & 0.92 & $0.72-1$ & 3.5 & 0.01 & 0.75 \\
\hline P11021 & HSPA5 & $78 \mathrm{kDa}$ glucose-regulated protein & 82 & 61 & $1.91 \mathrm{E}-04$ & 0.94 & $0.76-1$ & 1.9 & 0.09 & 0.75 \\
\hline P49321 & NASP & Nuclear autoantigenic sperm protein & 24 & 21 & 4.72E-03 & 0.96 & $0.83-1$ & 2.1 & 0.02 & 0.75 \\
\hline P40222 & TXLNA & Alpha-taxilin & 3 & 2 & $1.56 \mathrm{E}-03$ & 1.00 & - & 26 & 0.00 & 0.74 \\
\hline P80511 & S100A12 & Protein S100-A12 & 11 & 8 & $1.05 \mathrm{E}-02$ & 1.00 & - & 5.1 & 0.03 & 0.74 \\
\hline P07602 & PSAP & Prosaposin & 40 & 30 & 1.13E-04 & 0.98 & $0.88-1$ & 2.5 & 0.06 & 0.73 \\
\hline Q9NZZ3 & CHMP5 & Charged multivesicular body protein 5 & 3 & 2 & $1.55 \mathrm{E}-02$ & 0.98 & $0.88-1$ & 5.1 & 0.01 & 0.73 \\
\hline P35232 & PHB & Prohibitin & 5 & 2 & $3.62 \mathrm{E}-02$ & 0.94 & $0.76-1$ & 4 & 0.00 & 0.73 \\
\hline Q86V81 & $A L Y R E F$ & THO complex subunit 4 & 9 & 5 & $1.56 \mathrm{E}-03$ & 0.96 & $0.88-1$ & 2.4 & 0.02 & 0.73 \\
\hline O00515;P42766 & $L A D 1$ & Ladinin-1 & 31 & 24 & $4.61 \mathrm{E}-03$ & 1.00 & - & 1.5 & 0.02 & 0.73 \\
\hline P16949; Q93045 & STMN1 & Stathmin & 10 & 5 & 7.42E-03 & 0.94 & $0.76-1$ & 2.1 & 0.01 & 0.73 \\
\hline P04003 & C4BPA & C4b-binding protein alpha chain & 5 & 4 & 7.82E-03 & 1.00 & - & 6.7 & 0.01 & 0.72 \\
\hline O43399 & TPD52L2 & Tumor protein D54 & 10 & 5 & 4.85E-03 & 0.90 & $0.71-1$ & 1.7 & 0.03 & 0.72 \\
\hline Q04695 & KRT17 & Keratin, type I cytoskeletal 17 & 56 & 20 & $1.36 \mathrm{E}-02$ & 0.94 & $0.80-1$ & 2 & 0.04 & 0.72 \\
\hline P29034 & S100A2 & Protein S100-A2 & 6 & 6 & $1.83 \mathrm{E}-02$ & 0.86 & $0.64-1$ & 2 & 0.03 & 0.71 \\
\hline Q8WWX9 & SELM & Selenoprotein M & 3 & 2 & $7.88 \mathrm{E}-03$ & 0.90 & $0.67-1$ & 3.3 & 0.01 & 0.71 \\
\hline Q9P0L0 & VAPA & $\begin{array}{l}\text { Vesicle-associated membrane protein- } \\
\text { associated protein A }\end{array}$ & 7 & 4 & $5.08 \mathrm{E}-03$ & 0.90 & $0.66-1$ & 2.2 & 0.01 & 0.71 \\
\hline P30040 & ERP29 & $\begin{array}{l}\text { Endoplasmic reticulum resident protein } \\
29\end{array}$ & 22 & 16 & $4.98 \mathrm{E}-03$ & 0.94 & $0.74-1$ & 1.8 & 0.03 & 0.70 \\
\hline P54727 & $R A D 23 B$ & $\begin{array}{l}\text { UV excision repair protein RAD23 } \\
\text { homolog B }\end{array}$ & 10 & 5 & $1.24 \mathrm{E}-02$ & 0.94 & $0.76-1$ & 2.4 & 0.02 & 0.70 \\
\hline O14879 & IFIT3 & $\begin{array}{l}\text { Interferon-induced protein with } \\
\text { tetratricopeptide repeats } 3\end{array}$ & 9 & 5 & $5.80 \mathrm{E}-03$ & 0.98 & $0.88-1$ & 9.2 & 0.01 & 0.70 \\
\hline P07585 & $D C N$ & Decorin & 40 & 31 & 3.03E-03 & 1.00 & - & -4.6 & -0.12 & -0.70 \\
\hline Q5BKX8 & MURC & Muscle-related coiled-coil protein & 2 & 2 & $1.58 \mathrm{E}-03$ & 1.00 & - & -36.9 & -0.01 & -0.71 \\
\hline P02585 & TNNC2 & Troponin C, skeletal muscle & 48 & 41 & $1.06 \mathrm{E}-03$ & 1.00 & - & -11.5 & -0.14 & -0.71 \\
\hline P09493 & TPM1 & Tropomyosin alpha-1 chain & 74 & 26 & $6.71 \mathrm{E}-03$ & 1.00 & - & -5.4 & -0.12 & -0.72 \\
\hline P13646 & KRT13 & Keratin, type I cytoskeletal 13 & 61 & 31 & $1.24 \mathrm{E}-04$ & 1.00 & - & -6.2 & -0.09 & -0.72 \\
\hline P51888 & PRELP & Prolargin & 27 & 24 & 8.04E-04 & 1.00 & - & -5.7 & -0.09 & -0.72 \\
\hline O75112 & $L D B 3$ & LIM domain-binding protein 3 & 17 & 12 & 8.01E-03 & 0.98 & $0.92-1$ & -5.3 & -0.05 & -0.72 \\
\hline P04083 & ANXA1 & Annexin A1 & 98 & 74 & $5.83 \mathrm{E}-04$ & 1.00 & - & -2.8 & -0.18 & -0.73 \\
\hline P20774 & OGN & Mimecan & 30 & 26 & $1.31 \mathrm{E}-03$ & 1.00 & - & -5.9 & -0.06 & -0.73 \\
\hline P05976 & MYL1 & $\begin{array}{l}\text { Myosin light chain } 1 / 3 \text {, skeletal muscle } \\
\text { isoform }\end{array}$ & 77 & 55 & $6.70 \mathrm{E}-04$ & 1.00 & - & -12.3 & -0.24 & -0.74 \\
\hline Q9UKX2 & MYH2 & Myosin-2 & 127 & 33 & 1.17E-02 & 0.94 & $0.77-1$ & -2.1 & -0.06 & -0.74 \\
\hline P00568 & $A K 1$ & Adenylate kinase isoenzyme 1 & 27 & 15 & $2.16 \mathrm{E}-03$ & 1.00 & - & -3.8 & -0.06 & -0.74 \\
\hline
\end{tabular}

(continued on next page) 
Table 1 (continued)

\begin{tabular}{|c|c|c|c|c|c|c|c|c|c|c|}
\hline UniProt & Gene name & Protein name & All peptides & $\begin{array}{l}\text { Unique } \\
\text { peptides }\end{array}$ & Anova p-value & AUROC & $\begin{array}{l}\text { AUROC } \\
95 \% \mathrm{CI}\end{array}$ & $\begin{array}{l}\text { Fold } \\
\text { change }\end{array}$ & $\mathbf{p}[1]$ & $\begin{array}{l}\mathrm{p}(\text { corr }) \\
{[1]}\end{array}$ \\
\hline P31415 & CASQ1 & Calsequestrin-1 & 23 & 14 & $2.94 \mathrm{E}-04$ & 1.00 & - & -16.3 & -0.07 & -0.74 \\
\hline Q9UBG3 & CRNN & Cornulin & 55 & 46 & $1.21 \mathrm{E}-04$ & 1.00 & - & -5.4 & -0.20 & -0.75 \\
\hline P07951 & TPM2 & Tropomyosin beta chain & 83 & 28 & $9.48 \mathrm{E}-04$ & 1.00 & - & -3.9 & -0.14 & -0.76 \\
\hline P06753 & ТРМ3 & Tropomyosin alpha-3 chain & 67 & 25 & $3.25 \mathrm{E}-03$ & 0.98 & $0.88-1$ & -2.5 & -0.08 & -0.77 \\
\hline P51884 & $L U M$ & Lumican & 49 & 35 & $5.83 \mathrm{E}-03$ & 1.00 & - & -3.6 & -0.17 & -0.77 \\
\hline P48788 & TNNI2 & Troponin I, fast skeletal muscle & 19 & 11 & 1.19E-03 & 1.00 & - & -5.4 & -0.05 & -0.77 \\
\hline $\mathrm{P} 02144$ & $M B$ & Myoglobin & 71 & 59 & $1.31 \mathrm{E}-04$ & 1.00 & - & -21.5 & -0.25 & -0.78 \\
\hline P10916 & MYL2 & $\begin{array}{l}\text { Myosin regulatory light chain } 2 \text {, } \\
\text { ventricular/cardiac muscle isoform }\end{array}$ & 54 & 35 & $3.72 \mathrm{E}-04$ & 1.00 & - & -6.7 & -0.14 & -0.78 \\
\hline Q15847;Q9BZL4 & ADIRF & Adipogenesis regulatory factor & 8 & 6 & $1.01 \mathrm{E}-03$ & 1.00 & - & -4.9 & -0.04 & -0.78 \\
\hline Q6NZI2 & PTRF & Polymerase I and transcript release factor & 22 & 16 & 1.17E-02 & 0.96 & $0.82-1$ & -2.2 & -0.04 & -0.78 \\
\hline Q9BUF5 & TUBB6 & Tubulin beta- 6 chain & 14 & 6 & $2.26 \mathrm{E}-03$ & 0.94 & $0.74-1$ & -5.8 & -0.05 & -0.79 \\
\hline P08590 & $M Y L 3$ & Myosin light chain 3 & 39 & 26 & $5.86 \mathrm{E}-04$ & 0.98 & $0.88-1$ & -11.6 & -0.12 & -0.79 \\
\hline P17661 & DES & Desmin & 69 & 44 & 8.52E-04 & 1.00 & - & -3.3 & -0.06 & -0.81 \\
\hline Q16610 & ECM1 & Extracellular matrix protein 1 & 14 & 14 & $1.21 \mathrm{E}-04$ & 0.98 & $0.92-1$ & -3.7 & -0.03 & -0.81 \\
\hline P40926 & MDH2 & Malate dehydrogenase, mitochondrial & 16 & 11 & $2.30 \mathrm{E}-02$ & 0.92 & $0.76-1$ & -1.9 & -0.03 & -0.81 \\
\hline P30086 & PEBP1 & $\begin{array}{l}\text { Phosphatidylethanolamine-binding } \\
\text { protein } 1\end{array}$ & 22 & 17 & $6.30 \mathrm{E}-04$ & 1.00 & - & -2.2 & -0.06 & -0.81 \\
\hline Q9HCY8 & S100A14 & Protein S100-A14 & 13 & 10 & $1.38 \mathrm{E}-03$ & 1.00 & - & -2.9 & -0.03 & -0.81 \\
\hline Q8N1N4 & KRT78 & Keratin, type II cytoskeletal 78 & 11 & 5 & $3.91 \mathrm{E}-03$ & 0.96 & $0.84-1$ & -2.8 & -0.01 & -0.81 \\
\hline Q9NQ38 & SPINK5 & Serine protease inhibitor Kazal-type 5 & 57 & 35 & 7.72E-05 & 0.94 & $0.80-1$ & -2.4 & -0.05 & -0.82 \\
\hline P13805 & TNNT1 & Troponin $\mathrm{T}$, slow skeletal muscle & 7 & 5 & $1.29 \mathrm{E}-04$ & 1.00 & - & -5.8 & -0.02 & -0.82 \\
\hline P02511 & $C R Y A B$ & Alpha-crystallin B chain & 12 & 9 & $1.32 \mathrm{E}-05$ & 1.00 & - & -9.8 & -0.03 & -0.83 \\
\hline P14174 & $M I F$ & Macrophage migration inhibitory factor & 10 & 7 & $1.85 \mathrm{E}-03$ & 0.94 & $0.76-1$ & -2.2 & -0.07 & -0.83 \\
\hline $\begin{array}{c}\text { P19013;P14136; } \\
\text { Q6KB66 }\end{array}$ & KRT4 & Keratin, type II cytoskeletal 4 & 50 & 32 & 5.23E-04 & 1.00 & - & -3.3 & -0.07 & -0.85 \\
\hline P14649 & $M Y L 6 B$ & Myosin light chain 6B & 26 & 17 & 5.63E-05 & 0.98 & $0.88-1$ & -4.8 & -0.04 & -0.86 \\
\hline Q12836 & $Z P 4$ & Zona pellucida sperm-binding protein 4 & 2 & 2 & $1.52 \mathrm{E}-02$ & 0.86 & $0.57-1$ & -2.6 & -0.01 & -0.87 \\
\hline O60437;P80217 & $P P L$ & Periplakin & 104 & 59 & $1.16 \mathrm{E}-04$ & 1.00 & - & -1.9 & -0.07 & -0.88 \\
\hline 015231 & ZNF185 & Zinc finger protein 185 & 20 & 13 & $1.36 \mathrm{E}-04$ & 1.00 & - & -2.6 & -0.03 & -0.95 \\
\hline
\end{tabular}

colorectal carcinoma [19] and breast cancer, and knockdown in cancer cells induced G1 arrest [20]. Alpha-taxilin, with an AUROC of 1, is interesting through its absence in 5 of the 7 control samples. It has not been found in OSCC before, but in colorectal cancer its overexpression correlates with proliferation activity [21], and is associated with metastatic and invasive potential of renal cell carcinoma [22]. These may be of interest for future research in OSCC.

The two most upregulated proteins in stage IVa tumours, compared with stage I (Table 2), were KIAA1217 and protein NDRG1, both linked with proto-oncogenes. Little is known of KIAA1217 in cancer. It was recently discovered as a novel fusion partner gene with the RET protooncogene in one case of lung adenocarcinoma, whereby the fusion of RET with KIAA1217 led to activation of downstream signalling molecules: STAT3, AKT, and ERK. This was linked with increased tumour cell invasion in the study [23]. However, there are no further studies or reports of this protein in carcinoma progression. Also known as n-myc downstream-regulator protein 1, NDRG1 is a metastasis suppressor

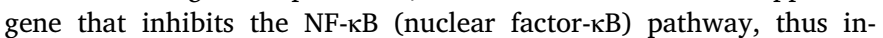
hibiting functions such as angiogenesis, proliferation, migration and invasion [24]. Its over-expression in OSCC has been linked in one study with long-term specific survival [25]. As the n numbers were small in our study, with three stage I and four stage IVa tumours, more investigation will be required to validate these results, especially with regards to the relatively unknown KIAA1217.

Three of the most significantly different proteins in the tissue proteomic analysis found on S-plot, that were also altered in serum OSCC compared to healthy [16], were S100A7, DEFA1 and CA1.

CA1 has been discovered in other tumours, such as breast cancer and small cell lung cancer (SCLC). In breast cancer, CA1 blockade with siRNA in tumour cell lines stimulated apoptosis and cell migration, suggesting that it may have an important role in mediating these processes [26]. Its upregulation in SCLC serum compared with benign lung disease patients, and healthy controls, caused it to be suggested as a potential biomarker [27]. Carbonic anhydrases are downstream proteins of hypoxia-inducible factor, which becomes stabilised under hypoxic conditions, for example in tumour cells, and mediates the transcription of proteins involved in glycolysis, angiogenesis and $\mathrm{pH}$ regulation [28]. Levels of CA1 in our study had a fold change of 3.4 in the tissue, compared with healthy samples. In the tumour tissue, CA1 immunopositivity was stronger than in controls. It has recently shown a similar upregulation in OSCC tissue using electrophoresis-based proteomics [14]. Other carbonic anhydrase family members IX and XII have been extensively investigated in cancers, including CAIX in OSCC [29]. There are some promising carbonic anhydrase inhibitors; phase 1 trials are currently underway for the selective carbonic anhydrase IX inhibitor SLC-0111 in patients with advanced solid tumours [30].

DEFA1 is produced by epithelial cells and neutrophils, and has been identified in multiple carcinomas, including overexpression in human oral tongue OSCC [31]. Another previous tongue OSCC study, which showed an association between neutrophil invasion and lymph node metastasis, higher stage, and increased rate of tumour recurrence, also demonstrated strong DEFA1 immunopositivity in neutrophils within tumour tissue but not in the surrounding tissue [32]. That study showed high protein fold changes in OSCC compared with control, similar to our fold change of 19.8 found with MS. In our study, IHC demonstrated DEFA1 immunopositivity in both inflammatory cells and tumour cells. Mild to moderate positivity was also seen in normal epithelia, however no particular staining of inflammatory cells in the control samples.

S100 proteins are known to be involved in tumours; some members as tumour suppressors and others act as tumour promotors [33]. S100A7 is a key player in tumour migration, invasion and induction of epithelial-mesenchymal transition, among others in OSCC [34]. In our study, S100A7 
Table 2

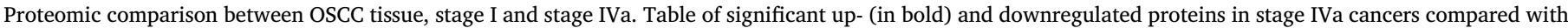

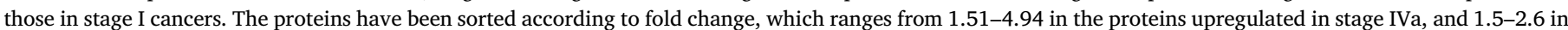

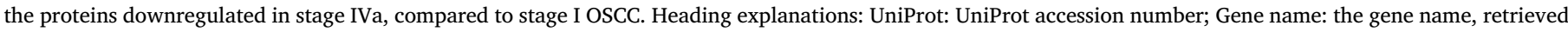

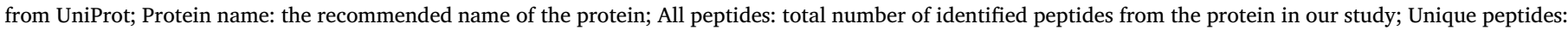

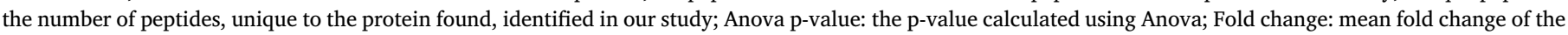

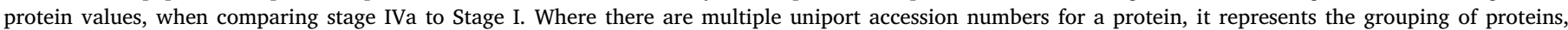
explained in Supplementary File 1 (page 3, line 21).

\begin{tabular}{|c|c|c|c|c|c|c|}
\hline UniProt & Gene name & Protein name & All peptides & Unique peptides & Anova p-value & Fold change \\
\hline Q5T5P2 & KIAA1217 & Sickle tail protein homolog & 4 & 2 & 0.021171 & 4.938 \\
\hline Q92597 & NDRG1 & Protein NDRG1 & 13 & 12 & 0.020015 & 4.124 \\
\hline P23434 & GCSH & Glycine cleavage system $\mathrm{H}$ protein, mitochondrial & 8 & 3 & 0.047383 & 1.542 \\
\hline Q01105;P0DME0 & $S E T$ & Protein SET & 24 & 17 & 0.024139 & 1.513 \\
\hline P07919;A0A096LP55 & UQCRH & Cytochrome b-c1 complex subunit 6 , mitochondrial & 9 & 9 & 0.047026 & -2.646 \\
\hline Q14568 & HSP90AA2P & Heat shock protein HSP 90-alpha A2 & 13 & 5 & 0.000494 & -2.612 \\
\hline P04259 & KRT6B & Keratin, type II cytoskeletal 6B & 73 & 2 & 0.030769 & -2.201 \\
\hline Q16610 & ECM1 & Extracellular matrix protein 1 & 14 & 14 & 0.042774 & -2.154 \\
\hline P06702 & S100A9 & Protein S100-A9 & 76 & 65 & 0.014422 & -2.049 \\
\hline O43768;P56211 & ENSA & Alpha-endosulfine & 7 & 5 & 0.049813 & -1.969 \\
\hline P13284 & IFI30 & Gamma-interferon-inducible lysosomal thiol reductase & 6 & 4 & 0.025037 & -1.959 \\
\hline Q9Y281 & CFL2 & Cofilin-2 & 17 & 3 & 0.044786 & -1.903 \\
\hline Q9HCY8 & S100A14 & Protein S100-A14 & 13 & 10 & 0.026441 & -1.832 \\
\hline P15311 & EZR & Ezrin & 43 & 15 & 0.006186 & -1.767 \\
\hline P07951 & TPM2 & Tropomyosin beta chain & 83 & 28 & 0.006667 & -1.67 \\
\hline Q9H3N1 & $T M X 1$ & Thioredoxin-related transmembrane protein 1 & 2 & 2 & 0.018378 & -1.623 \\
\hline Q96FQ6 & S100A16 & Protein S100-A16 & 8 & 7 & 0.007353 & -1.545 \\
\hline
\end{tabular}

expression was detected in all tumour samples. Interestingly, there was heterogeneity in positivity in the tumour tissue, shown in Fig. 4. In head and neck squamous cell carcinoma (HNSCC), nuclear S100A7 has been associated with reduced disease-free survival [35]. Members of the S100 protein family are differently expressed in various cancers - expression patterns depend on the tumour, its subtype and stage [33]. In HNSCC, the majority of the $\mathrm{S} 100$ proteins are downregulated whereas in most other cancers they tend to be upregulated (33), contrasting with our findings of

A

Principal Component Analysis

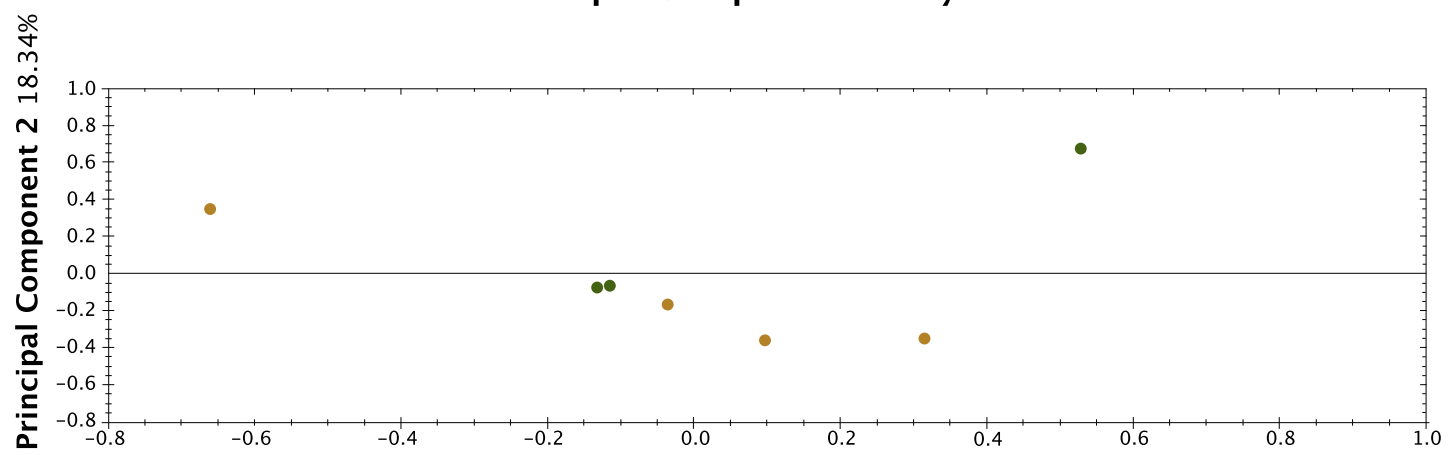

Principal Component 1 46.27\%

B

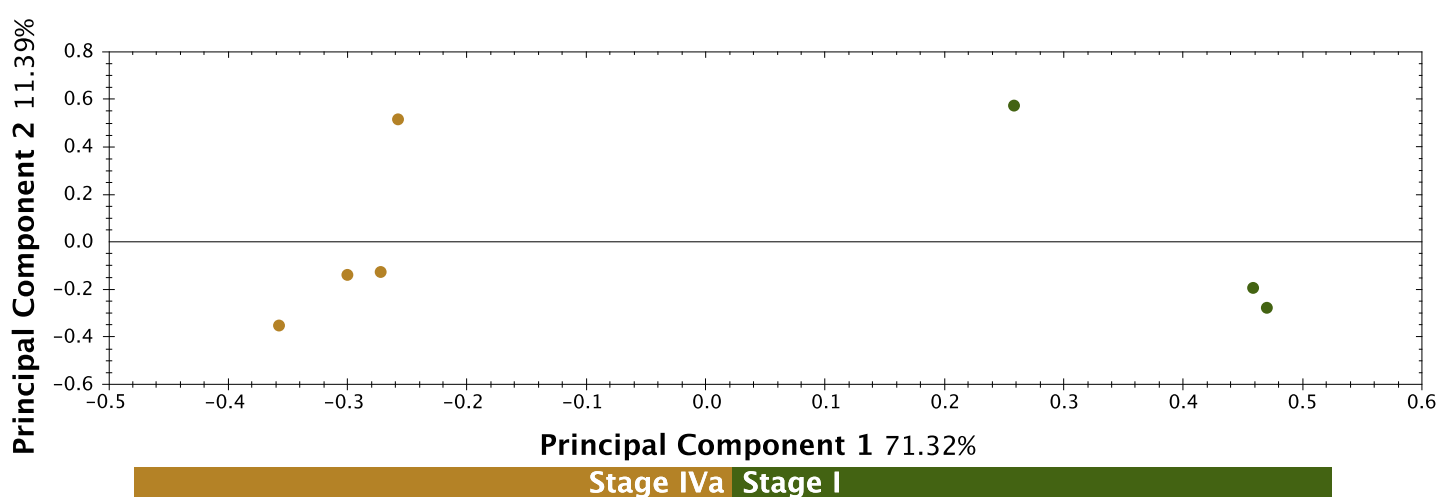

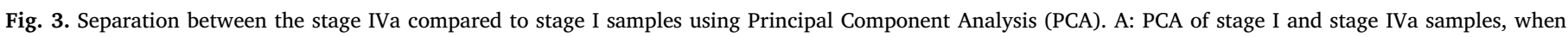

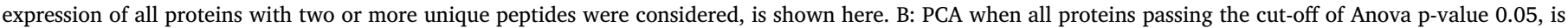
shown here. 


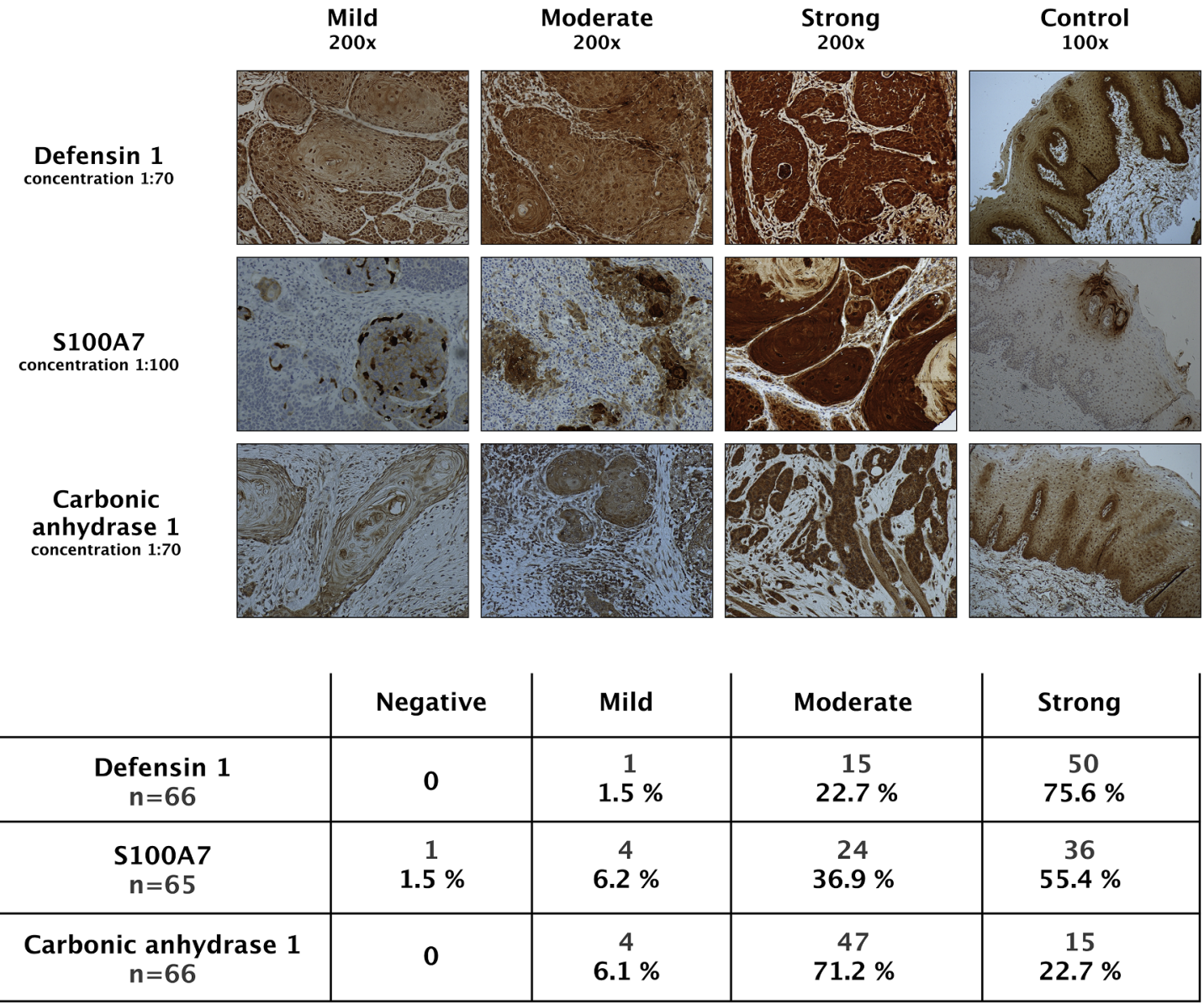

Fig. 4. Immunohistochemistry of S100A7, neutrophil defensin 1, and carbonic anhydrase 1 . The top composite image shows immunohistochemical staining patterns using: anti-defensin 1 antibodies (first row of images); anti-S100A7 antibodies (second row of images); anti-carbonic anhydrase 1 antibodies (third row) in the tumour samples at 200x magnification. Control images are on the right-hand panel at 100x magnification to show the whole epithelial layer. The images were taken with a Nicon Eclipse 80i microscope. Below the composite image are the numbers and percentage of tumours with different staining intensities for each antibody, expressed in a tabular format.

other S100 proteins S100A2, 7, 7A, 12 being significantly upregulated in the OSCCs, which could be the particular pattern in tongue cancer. Clinical trials are ongoing for targeting other S100 proteins, like S100B in melanoma [36], confirming that there is a possibility to target these proteins therapeutically.

\section{Pathway analysis}

One aim of our study was to gain insight into the pathways and networks upregulated in the tongue cancer compared with healthy tongue tissue from the same patient. The canonical pathways (Supplementary Fig. 1) involved in OSCC include calcium signalling, cell-to-cell interaction signalling, and immune system pathways involving phagocytes, amongst others.

Calcium signalling has a fundamental biological role, evolutionarily developed to be at the centre of almost all cellular processes, including signalling between cells, transcription, motility, innate immunity and apoptosis [37]. In cancer cells the calcium homeostasis is disrupted, as can be seen as the top canonical pathway involved. It is well established that calcium signalling alterations are implicated in tumour induction, angiogenesis, proliferation and metastasis [38]. Other examples of alterations are that, calcium-regulated membrane protein mutations, such as the IP3R (Inositol triphosphate receptor), have been detected in HNSCC [39], and the PMCA1 (plasma membrane Ca2 + ATPase isoform 1) calcium transporter expression has been found to be downregulated in OSCC [38]. In our samples, a handful of calcium related proteins were upregulated, including but not limited to calreticulin, calponin 1 and 3, reticulocalbin, S100 proteins, which were upregulated, and calsequestrin was downregulated.

The network most enriched with the S-plot proteins, suggesting the most disrupted networks, was 'Cellular Movement, Haematological System Development and Function, Immune Cell Trafficking', linking in with the calcium signalling and other top canonical pathways. This network was almost completely enriched in S-plot proteins (Fig. 5). It centres around NF-kB and MAPK (mitogen activated protein kinase), and contains multiple groups of proteins such as the S100s and the keratins amongst others. NF- $\mathrm{kB}$ plays a role in the regulation of various genes, including matrix metalloproteinases, anti-apoptotic factors, adhesion molecules, cytokines [40]. MAPKs are involved in the regulation of cell differentiation, proliferation and death in OSCC [41].

In addition to their important role in mechanical stability and structural integrity of epithelial cells, keratins have additional functions including protection from stress, wound healing and apoptosis [42]. Expression of keratin isoforms differs in various cancers, reflecting tumour activity, and they thus have the potential to serve as prognostic markers as fragments of the cytokeratins have been demonstrated in the circulation. The cytokeratin detection tests known as TPA, which measures cytokeratins 8,18 and 19 in the serum, and CYFRA- 1 , which measures soluble cytokeratin 18 fragments, have been documented in various epithelial cell related tumours including head and neck cancers [43], as ways to monitor progression and response to treatment. KRT17 has been suggested as a diagnostic marker for OSCC and is highly 


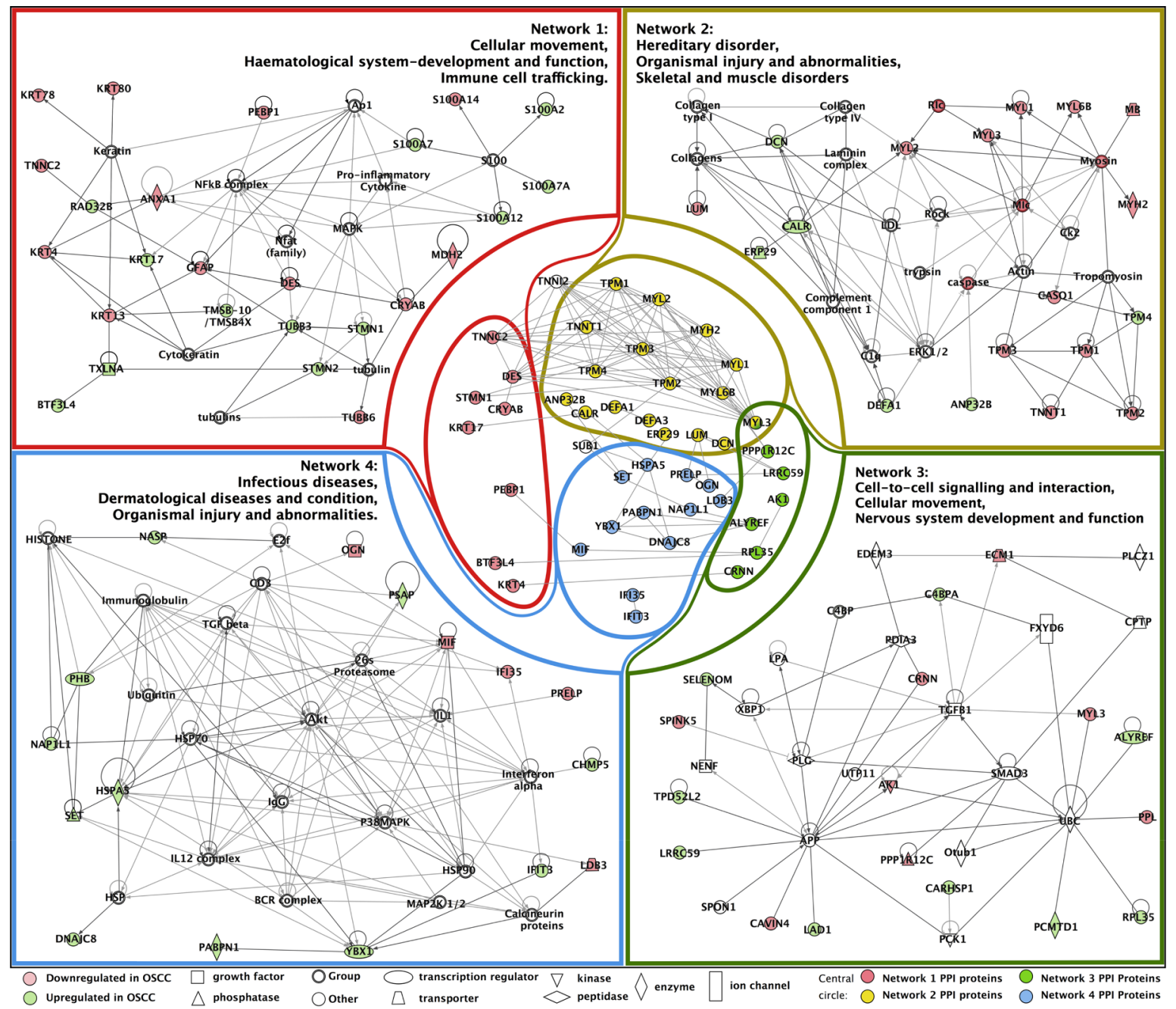

Fig. 5. Protein-protein interaction (PPI) networks of proteins found to be significantly different between OSCC tissue and healthy tissue by S-plot. The central circle shows PPI networks obtained using String. In each corner are the top four PPI networks obtained using Ingenuity Pathways Analysis (IPA), which also include proteins with which the proteins, identified in our study, are known to interact. The names of the networks are given in each rectangle. The coloured rings in the central area correspond to interactions, which were overlapping between String networks and IPA networks. In the corner boxes, corresponding to IPA networks, the proteins found in our study are coloured, and the key shows the function of each protein and whether it was upregulated or downregulated in OSCC. This diagram highlights the overlap between two different algorithms (IPA and String).

upregulated in the OSCC tissue on IHC [44]. In one study, KRT17 with low KRT13 was suggestive of malignant changes within oral lesions [45], which correlates with our results of downregulated KRT13 (FC -6.19) and upregulated KRT17 (FC 1.98) in the tumour tissue.

\section{Conclusions}

We have shown that based on tissue proteomics, tongue cancer tissue samples can be separated from samples of healthy adjacent tissue. With an MS technique, we were able to identify a set of 35 upregulated and 37 downregulated statistically relevant proteins that most reliably represent this separation, many of which were novel in OSCC. These proteins were found to participate in processes including calcium signalling, epithelial integrity, neutrophil functioning, and cellular movement. There were some overlapping proteins compared to previous proteomic analysis however several novel proteins were detected, such as alpha-taxilin. Additionally, we show that KIAA1217 and NDRG1 are upregulated in stage IVa OSCC compared with stage I. We need further research to clarify whether the expression of some of these key proteins could serve as a potential biological classification component of different OSCC tumours.

\section{Availability of data and material}

The datasets supporting the conclusions of this article are available in the ProteomeXchange repository, PXD009244 for tissue data and PXD005263 for serum data $[16,17] \mathrm{http} / / /$ proteomecentral. proteomexchange.org/cgi/GetDataset.

\section{Conflicts of interest}

None.

\section{Acknowledgements}

Thank you to Päivi Peltokengas for her contribution to the IHC wet lab, to Rayan Mroueh for his contribution to the TMA block patient information, and to Rahul Agarwal for his assistance with statistical analysis.

Funding was provided by Jane \& Aatos Erkko Foundation, University of Helsinki Medical Faculty, and the Finnish Foundation for Ear, Nose and Throat Research (Korvatautien Tutkimussäätiö), and the Helsinki University Hospital Research Fund, who all supported the entire research from study design to manuscript writing, and Emil 
Aaltonen Research Foundation, grant number (180025 N1) and Finnish-Norwegian Foundation for Medicine, grant number (201800155), who supported the revision of the manuscript.

\section{Appendix A. Supplementary material}

Supplementary data to this article can be found online at https:// doi.org/10.1016/j.oraloncology.2018.09.013.

\section{References}

[1] Annertz K, Anderson H, Palmer K, Wennerberg J. The increase in incidence of cancer of the tongue in the Nordic countries continues into the twenty-first century. Acta Otolaryngol 2012;132(5):552-7.

[2] Chaturvedi AK, Anderson WF, Lortet-Tieulent J, Curado MP, Ferlay J, Franceschi S, et al. Worldwide trends in incidence rates for oral cavity and oropharyngeal cancers. J Clin Oncol 2013;31(36):4550-9.

[3] Braakhuis BJ, Leemans CR, Visser O. Incidence and survival trends of head and neck squamous cell carcinoma in the Netherlands between 1989 and 2011. Oral Oncol 2014;50(7):670-5.

[4] UK CR. Survival | Mouth (oral) cancer | Cancer Research UK: Cancer Research UK; 2016 [updated 06 July 2016. Available from: http://www.cancerresearchuk.org/ about-cancer/mouth-cancer/survival.

[5] Siegel RL, Miller KD, Jemal A. Cancer statistics, 2016. CA Cancer J Clin 2016;66(1):7-30.

[6] Mroueh R, Haapaniemi A, Grenman R, Laranne J, Pukkila M, Almangush A, et al Improved outcomes with oral tongue squamous cell carcinoma in Finland. Head Neck 2017;39(7):1306-12.

[7] Pathare SM, Gerstung M, Beerenwinkel N, Schaffer AA, Kannan S, Pai P, et al. Clinicopathological and prognostic implications of genetic alterations in oral cancers. Oncol Lett 2011;2(3):445-51.

[8] Blatt S, Kruger M, Ziebart T, Sagheb K, Schiegnitz E, Goetze E, et al. Biomarkers in diagnosis and therapy of oral squamous cell carcinoma: a review of the literature. $\mathrm{J}$ Craniomaxillofac Surg 2017;45(5):722-30.

[9] Subarnbhesaj A, Miyauchi M, Chanbora C, Mikuriya A, Nguyen PT, Furusho H, et al. Roles of VEGF-Flt-1 signaling in malignant behaviors of oral squamous cell carcinoma. PLoS ONE 2017;12(11):e0187092.

[10] Cui Z, Cui Y, Luo G, Yang S, Ling X, Lou Y, et al. Kallikrein-related peptidase 4 contributes to the tumor metastasis of oral squamous cell carcinoma. Biosci Biotechnol Biochem 2017;81(9):1768-77.

[11] Lee JR, Roh JL, Lee SM, Park Y, Cho KJ, Choi SH, et al. Overexpression of glutathione peroxidase 1 predicts poor prognosis in oral squamous cell carcinoma. $J$ Cancer Res Clin Oncol 2017;143(11):2257-65.

[12] Chanthammachat P, Promwikorn W, Pruegsanusak K, Roytrakul S, Srisomsap C, Chokchaichamnankit D, et al. Comparative proteomic analysis of oral squamous cell carcinoma and adjacent non-tumour tissue from Thailand. Arch Oral Biol 2013:58(11):1677-85.

[13] Chen J, He QY, Yuen AP, Chiu JF. Proteomics of buccal squamous cell carcinoma: the involvement of multiple pathways in tumorigenesis. Proteomics 2004:4(8):2465-75.

[14] Ananthi S, Lakshmi CNP, Atmika P, Anbarasu K, Mahalingam S. Global quantitative proteomics reveal deregulation of cytoskeletal and apoptotic signalling proteins in oral tongue squamous cell carcinoma. Sci Rep 2018;8(1):1567.

[15] Oliveira BM, Coorssen JR, Martins-de-Souza D. 2DE: the phoenix of proteomics. J Proteomics 2014;104:140-50.

[16] Saraswat M, Makitie A, Agarwal R, Joenvaara S, Renkonen S. Oral squamous cell carcinoma patients can be differentiated from healthy individuals with label-free serum proteomics. Br J Cancer 2017;117(3):376-84.

[17] Saraswat MMA, Agarwal R, Joenvaara S, Renkonen S. Novel diagnostic biomarkers in serum identify patients with OSCC. Proteome Exchange Consortium; 2017. $<$ http://proteomecentral.proteomexchange.org/cgi/GetDataset?ID = PXD005263>

[18] Dey KK, Pal I, Bharti R, Dey G, Kumar BN, Rajput S, et al. Identification of RAB2A and PRDX1 as the potential biomarkers for oral squamous cell carcinoma using mass spectrometry-based comparative proteomic approach. Tumour Biol 2015;36(12):9829-37.

[19] Uzozie AC, Selevsek N, Wahlander A, Nanni P, Grossmann J, Weber A, et al. Targeted proteomics for multiplexed verification of markers of colorectal tumorigenesis. Mol Cell Proteomics 2017;16(3):407-27.

[20] Yang S, Zhou L, Reilly PT, Shen SM, He P, Zhu XN, et al. ANP32B deficiency impairs proliferation and suppresses tumor progression by regulating AKT phosphorylation. Cell Death Dis 2016;7:e2082.

[21] Kanamori A, Imai Y, Ihara K, Nagata H, Nakano M, Tominaga K, et al. alpha-taxilin overexpression correlates with proliferation activity but not with prognosis of colorectal cancer. Oncol Lett 2017;14(2):1471-6.

[22] Mashidori T, Shirataki H, Kamai T, Nakamura F, Yoshida K. Increased alpha-taxilin protein expression is associated with the metastatic and invasive potential of renal cell cancer. Biomed Res 2011;32(2):103-10.

[23] Lee MS, Kim RN, H I, Oh DY, Song JY, Noh KW, et al. Identification of a novel partner gene, KIAA1217, fused to RET: functional characterization and inhibitor sensitivity of two isoforms in lung adenocarcinoma. Oncotarget 2016;7(24):36101-14.

[24] Xi R, Pun IH, Menezes SV, Fouani L, Kalinowski DS, Huang ML, et al. Novel thiosemicarbazones inhibit lysine-rich carcinoembryonic antigen-related cell adhesion molecule 1 (CEACAM1) coisolated (LYRIC) and the LYRIC-induced epithelial-mesenchymal transition via upregulation of N-Myc downstream-regulated gene 1 (NDRG1). Mol Pharmacol 2017;91(5):499-517.

[25] Dos Santos M, da Cunha Mercante AM, Nunes FD, Leopoldino AM, de Carvalho MB, Gazito D, et al. Prognostic significance of NDRG1 expression in oral and oropharyngeal squamous cell carcinoma. Mol Biol Rep 2012;39(12):10157-65.

[26] Zheng Y, Xu B, Zhao Y, Gu H, Li C, Wang Y, et al. CA1 contributes to microcalcification and tumourigenesis in breast cancer. BMC Cancer 2015;15:679.

[27] Wang DB, Lu XK, Zhang X, Li ZG, Li CX. Carbonic anhydrase 1 is a promising biomarker for early detection of non-small cell lung cancer. Tumour Biol 2016;37(1):553-9.

[28] Supuran CT. Carbonic Anhydrase inhibition and the management of hypoxic tumors. Metabolites 2017;7(3).

[29] Yang JS, Lin CW, Chuang CY, Su SC, Lin SH, Yang SF. Carbonic anhydrase IX overexpression regulates the migration and progression in oral squamous cell carcinoma. Tumour Biol 2015;36(12):9517-24.

[30] A phase I, multi-center, open-label, study to investigate the safety, tolerability and pharmacokinetic of SLC-0111 in subjects with advanced solid tumours. 2016 [15 January 2018]. Available from: https://clinicaltrials.gov/ct2/show/NCT02215850.

[31] Lundy FT, Orr DF, Gallagher JR, Maxwell P, Shaw C, Napier SS, et al. Identification and overexpression of human neutrophil alpha-defensins (human neutrophil peptides 1, 2 and 3) in squamous cell carcinomas of the human tongue. Oral Oncol 2004:40(2):139-44.

[32] Wang N, Feng Y, Wang Q, Liu S, Xiang L, Sun M, et al. Neutrophils infiltration in the tongue squamous cell carcinoma and its correlation with CEACAM1 expression on tumor cells. PLoS ONE 2014;9(2):e89991.

[33] Bresnick AR, Weber DJ, Zimmer DB. S100 proteins in cancer. Nat Rev Cancer 2015;15(2):96-109.

[34] Dey KK, Bharti R, Dey G, Pal I, Rajesh Y, Chavan S, et al. S100A7 has an oncogenic role in oral squamous cell carcinoma by activating p38/MAPK and RAB2A signaling pathway. Cancer Gene Ther 2016;23(11):382-91.

[35] Tripathi SC, Matta A, Kaur J, Grigull J, Chauhan SS, Thakar A, et al. Nuclear S100A7 is associated with poor prognosis in head and neck cancer. PLoS ONE 2010;5(8):e11939.

[36] 0794GCC: Pentamidine in Treating Patients With Relapsed or Refractory Melanoma [Internet]. Bethesda (MD): National Library of Medicine (US). August 8, 2008 [cited March 30, 2017]. Available from: https://ClinicalTrials.gov/show/NCT00729807.

[37] Clapham DE. Calcium signaling. Cell 2007;131(6):1047-58.

[38] Cui C, Merritt R, Fu L, Pan Z. Targeting calcium signaling in cancer therapy. Acta Pharm Sin B 2017;7(1):3-17.

[39] Hedberg ML, Goh G, Chiosea SI, Bauman JE, Freilino ML, Zeng Y, et al. Genetic landscape of metastatic and recurrent head and neck squamous cell carcinoma. J Clin Invest 2016;126(1):169-80.

[40] Tang D, Tao D, Fang Y, Deng C, Xu Q, Zhou J. TNF-alpha promotes invasion and metastasis via NF-Kappa B pathway in oral squamous cell carcinoma. Med Sci Monit Basic Res 2017;23:141-9.

[41] Peng Q, Deng Z, Pan H, Gu L, Liu O, Tang Z. Mitogen-activated protein kinase signaling pathway in oral cancer. Oncol Lett 2018;15(2):1379-88.

[42] Moll R, Divo M, Langbein L. The human keratins: biology and pathology. Histochem Cell Biol 2008;129(6):705-33.

[43] Barak V, Goike H, Panaretakis KW, Einarsson R. Clinical utility of cytokeratins as tumor markers. Clin Biochem 2004;37(7):529-40.

[44] Mikami Y, Fujii S, Nagata K, Wada H, Hasegawa K, Abe M, et al. GLI-mediated Keratin 17 expression promotes tumor cell growth through the anti-apoptotic function in oral squamous cell carcinomas. J Cancer Res Clin Oncol 2017;143(8):1381-93.

[45] Kitamura R, Toyoshima T, Tanaka H, Kawano S, Kiyosue T, Matsubara R, et al. Association of cytokeratin 17 expression with differentiation in oral squamous cell carcinoma. J Cancer Res Clin Oncol 2012;138(8):1299-310. 